\title{
Perawatan Pergeseran Mandibula dan Kliking Menggunakan Teknik Edgewise dan Trainer
}

\author{
Rully Utami, Wayan Ardhana, dan Christnawati \\ Program Studi Ortodonsia, PPDGS, Fakultas Kedokteran Gigi, Universitas Gadjah Mada \\ JI Denta No 1 Sekip Utara, Yogyakarta, Indonesia; e-mail: rully.dentist@yahoo.com
}

\begin{abstract}
ABSTRAK
Kasus ini terjadi pada perempuan usia 22 tahun yang bersedia dipublikasikan untuk kepentingan ilmu pengetahuan Keluhan utama mandibula dan dagunya bergeser ke kanan, gigitan terbuka posterior dan bunyi click di persendian temporomandibular. Diagnosis pasien adalah maloklusi Angle kelas III tipe dento skeletal, pergeseran garis tengah mandibula dan dagu ke kanan, gigitan terbuka posterior dan clicking pada sendi temporomandibular. Perawatan dilakukan dengan teknik Edgewise dan trainer. Leveling dan unraveling dilakukan menggunakan kawat stainless steel bulat diameter 0,014 mm dengan multiloop. Trainer digunakan untuk koreksi pergeseran mandibula. Perawatan dilakukan selama 11 bulan, dan menunjukkan hasil hubungan molar pertama kanan menjadi kelas I. Overjet meningkat dari 0,1 $\mathrm{mm}$ menjadi $2 \mathrm{~mm}$, overbite meningkat dari $0,2 \mathrm{~mm}$ menjadi $2,57 \mathrm{~mm}$, garis tengah mandibula yang semula bergeser ke kanan 4,38 mm menjadi $2,53 \mathrm{~mm}$, gigitan terbuka posterior dan clicking telah terkoreksi.

Maj Ked Gi. Juni 2014; 21(1):91-96
\end{abstract}

Kata kunci: maloklusi kelas III, pergeseran mandibula, clicking, teknik Edgewise, trainer ortodontik

\begin{abstract}
Compromised Treatment of Class III Malocclusion with Mandibular Shifting, Posterior Openbite and Clicking Using Edgewise Technique and Trainer In Adult. This case report described the treatment of an adult female 22 years old who complained that her mandibula and chin shift to the right, posterior openbite and clicking. The patient diagnosed class III molar relationship, skeletal class III malocclusion, mandibular midline and chin shift to the right, posterior openbite and clicking on temporomandibular joint. Treatment was conducted using combination between Edgewise Technique and trainer. Leveling and unraveling are achieved by round stainless steel archwire 0,014 $\mathrm{mm}$ with multiloop. Trainer used to corrected the mandibular shifting. Result after 1 years treatment showed that the right molar relationship became class l, overjet increased from $0,1 \mathrm{~mm}$ to $2 \mathrm{~mm}$, overbite increased from 0,2 $\mathrm{mm}$ to $2,57 \mathrm{~mm}$, mandibular midline shifting decresed from 4,38 $\mathrm{mm}$ to 2,53 $\mathrm{mm}$, posterior openbite and clicking have been corrected. Maj Ked Gi. Juni 2014; 21(1):91-96
\end{abstract}

Keywords: class III malocclusion, mandibular shifting, clicking, Edgewise technique, orthodontic trainer

\section{PENDAHULUAN}

Maloklusi kelas III merupakan maloklusi yang sangat mudah dikenali akan tetapi seringkali sulit untuk melakukan perawatan. Keberhasilan perawatan maloklusi sangat bergantung pada beberapa faktor, diantaranya pengetahuan pola tumbuh kembang dentomaksilofasial, diagnosis, etiologi, perencanaaan perawatan, dan pemilihan metode dan alat dalam melakukan perawatan maloklusi. ${ }^{1}$

Faktor penyebab maloklusi kelas III diantaranya adalah faktor hereditas. Maloklusi kelas III dapat juga disebabkan oleh faktor lingkungan seperti kebiasaan dan bernafas melalui mulut. Etiologi lain dari maloklusi kelas III adalah posisi memajukan mandibula secara habitual karena adanya prematur kontak. ${ }^{2}$

Perawatan kamuflase pada maloklusi kelas III dengan pergeseran mandibula dan openbite posterior dapat dilakukan dengan pergerakan dentoalveolar. Elastik kelas III dengan atau tanpa pencabutan gigi telah digunakan untuk perawatan kamuflase diskrepansi skeletal, yang dapat menghasilkan perbaikan profil muka. ${ }^{2}$

Gangguan oklusi sering ditemui dan selalu dianggap sebagai penyebab utama terjadinya penyakit pada sendi temporomandibular. Hasil studi epidemiologi, lebih dari $75 \%$ orang dewasa memperlihatkan gejala gangguan oklusi seperti clicking dan bentuk serta posisi yang abnormal dari 


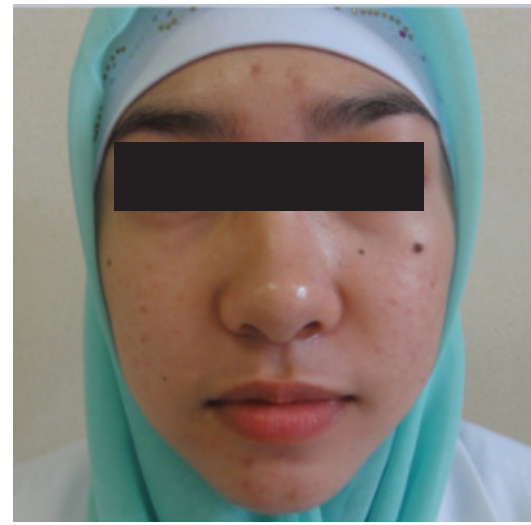

(A)

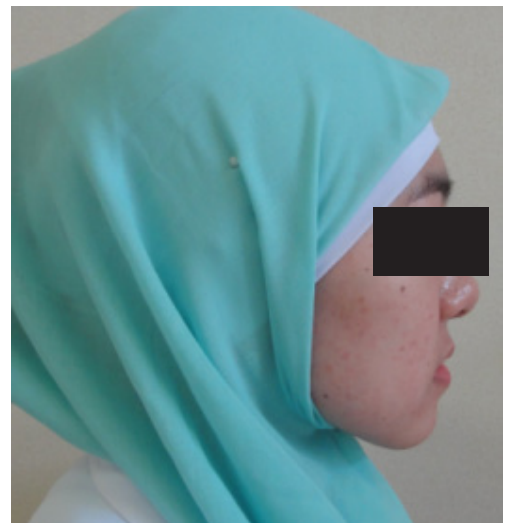

(B)

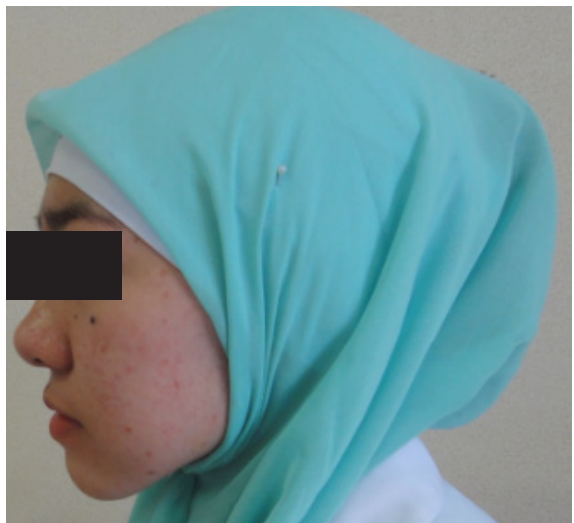

(C)

Gambar 1. Fotogram ekstra oral sebelum perawatan ortodontik : (A) Bentuk muka asimetri dagu bergeser ke kanan dan posisi bibir sebelah kanan pada waktu istirahat terbuka; (B)Tampak samping kanan; (C)Tampak samping kiri

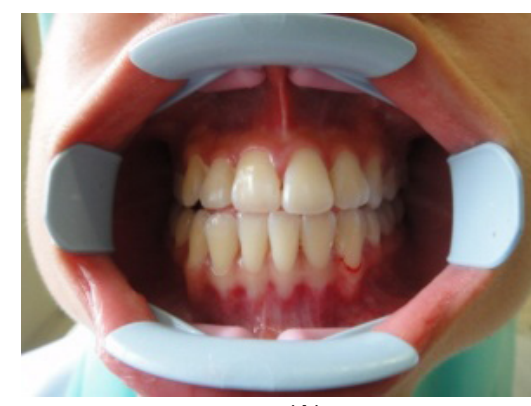

(A)

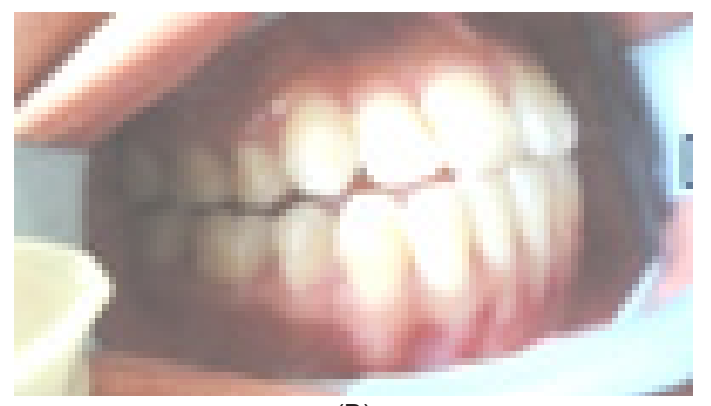

(B)

Gambar 2. Fotogram intra oral sebelum perawatan ortodontik: A. Edge to edge bite; B. Openbite posterior

mandibula pada saat dilakukan pemeriksaan klinis. ${ }^{3}$ Clicking adalah bunyi singkat yang terjadi pada saat membuka atau menutup mulut, bahkan keduanya. Clicking dapat terjadi pada awal, pertengahan, dan akhir membuka dan menutup mulut. Bunyi click yang terjadi pada akhir membuka mulut menandakan adanya suatu pergeseran sendi yang berat. ${ }^{4}$ Clicking pada sendi temporo mandibular sulit didengar karena bunyinya halus, maka dapat didengar dengan menggunakan stetoskop. ${ }^{5}$

Teknik Edgewise yang menggabungkan multiple loops dengan elastik intermaksilar dapat memberikan gerakan gigi individual, mengubah inklinasi dataran oklusal, koreksi hubungan sagital oklusal, dan menghasilkan kontak interkuspal yang benar dalam waktu lebih pendek. Perubahan utama setelah perawatan dengan teknik Edgewise adalah kompensasi dentoalveolar. ${ }^{6}$
Perawatan untuk koreksi gangguan oklusi atau kelainan gigitan seperti pergeseran mandibula, pada umumnya menggunakan suatu alat yang biasa disebut trainer dibuat dan dipasang pada gigi-gigi, dipergunakan pada malam hari namun mungkin diperlukan sepanjang hari. Perawatan ini diperlukan untuk koreksi pergeseran mandibula. ${ }^{3}$ Gigitan abnormal oleh karena faktor kebiasaan oklusi yang salah dikoreksi dengan pemakaian alat stabilisasi individual. ${ }^{7}$

\section{METODE}

Pasien perempuan, umur 22 tahun, suku Melayu dan bersedia dipublikasikan untuk kepentingan ilmu pengetahuan. Datang ke klinik Ortodonsia Program Pendidikan Dokter Gigi Spesialis Fakultas Kedokteran Gigi Universitas 


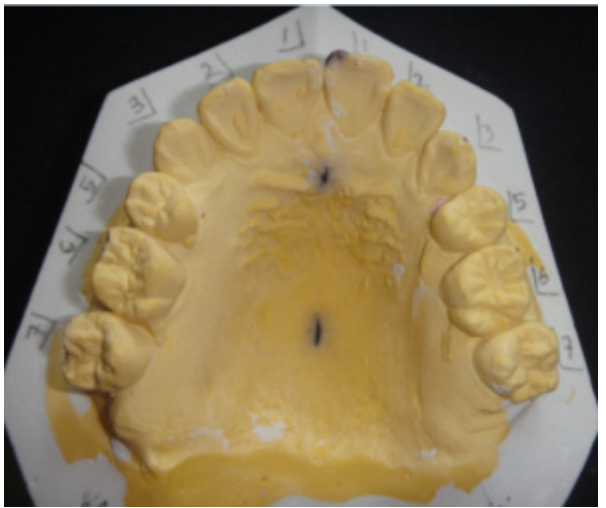

(A)

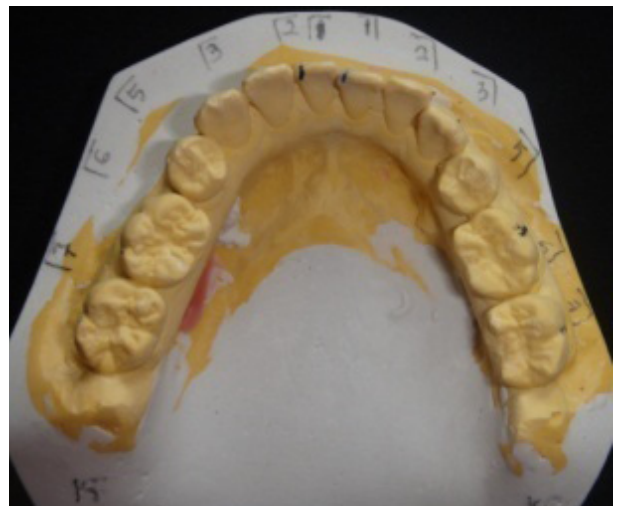

(B)

Gambar 3. Fotogram model studi gigi sebelum perawatan ortodontik :(A). Lengkung gigi rahang atas simetri; (B). Lengkung gigi rahang bawah asimetri

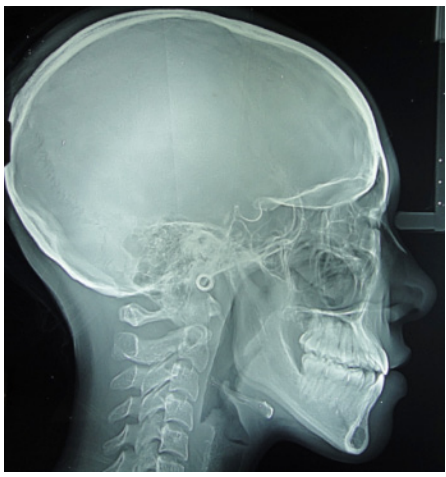

(A)

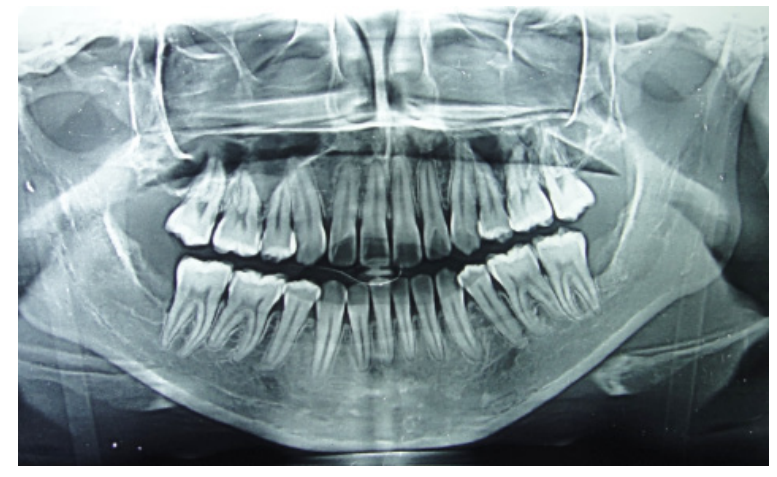

(B)

Gambar 4. (A) Foto sefalogram lateral hubungan skeletal klas III; (B) Panoramik sebelum perawatan ortodontik keempat gigi molar ketiga sudah dicabut

Gadjah Mada dengan keluhan merasa terganggu karena gigitan gigi miring ke kanan dan gigitan gigi belakang kanan yang terbuka sehingga sulit untuk mengunyah makanan. Pasien pernah dirawat menggunakan alat cekat dua tahun yang lalu dengan keluhan awal gigi taring yang tumbuh terlalu ke atas, dan dilakukan pencabutan empat gigi premolar pertama dan empat gigi molar ketiga. Pemeriksaan klinis menunjukkan status gizi normal, tidak menderita penyakit yang dapat mempengaruhi perawatan,profil muka cembung, bentuk muka asimetri dagu bergeser ke kanan. Posisi bibir sebelah kanan pada waktu posisi istirahat terbuka.

Pemeriksaan model studi menunjukkan gigi $14,24,34,44$ sudah dilakukan pencabutan, overjet : $0,1 \mathrm{~mm}$, overbite : $0,2 \mathrm{~mm}$, openbite pada relasi gigi 12131516 dan 424345 46, edge to edge bite pada relasi gigi 11 dan $41 ; 22$ dan 33 ; 25 dan 35 ; 26 dan 36, relasi gigi molar pertama kanan dan kiri kelas III Angle. Garis tengah mandibula terhadap maksila bergeser ke kanan 4,38 $\mathrm{mm}$. Pemeriksaan sefalogram lateral menggunakan metode Steiner menunjukkan hubungan skeletal kelas III dengan bidental protrusif. Pemeriksaan radiografi panoramik menunjukkan gigi 14, 24, 34, 44, 18, 28, 38, 48 sudah dicabut. Pemeriksaan auskultasi pada sendi temporomandibular menunjukkan clicking terjadi disaat pasien membuka dan menutup mulut.

\section{Rencana Perawatan dan Tujuan perawatan}

Pencarian ruang pada rahang atas dilakukan dengan ekspansi lateral, pada rahang bawah dilakukan grinding mesial distal gigi $31,32,33,35$, 


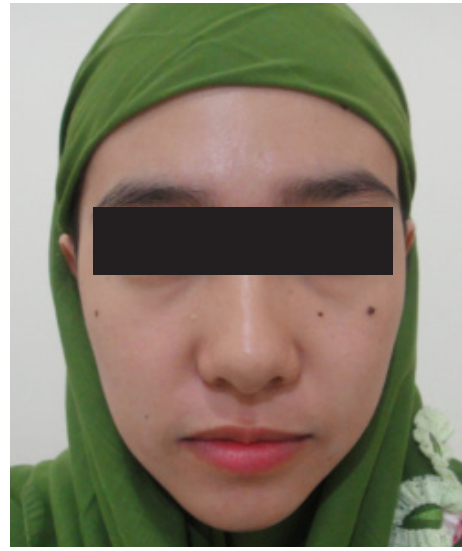

(A)

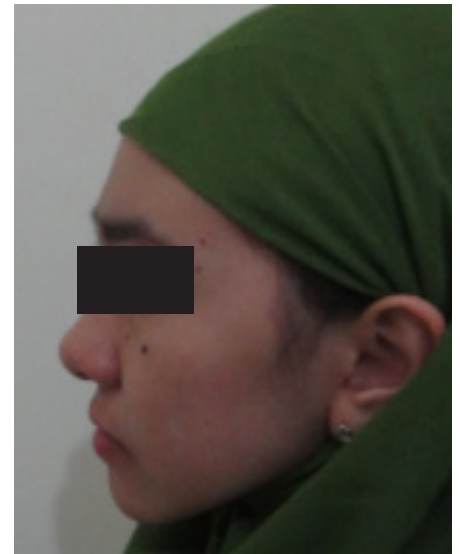

(B)

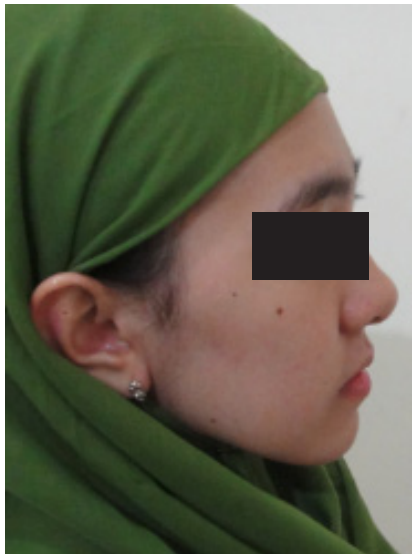

(C)

Gambar 7. Fotogram ekstra oral setelah perawatan ortodontik asimetri wajah terkoreksi ; (A).Tampak depan; (B).Tampak samping kanan; (C).Tampak samping kiri

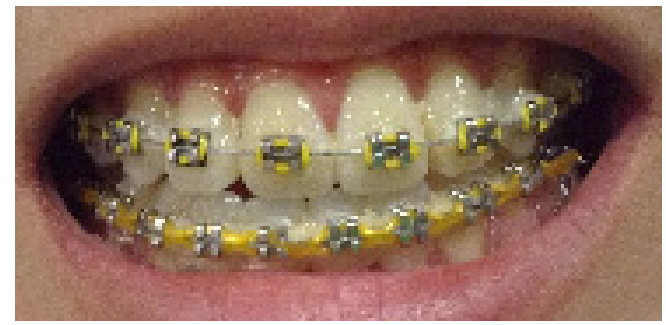

(A)

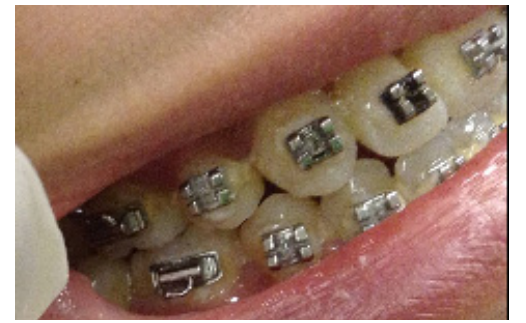

(B)

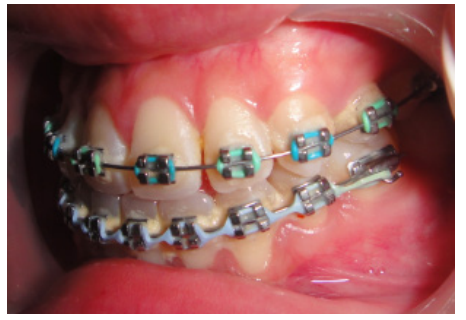

(C)

Gambar 8. Fotogram Intra oral setelah perawatan : (A).Tampak depan; (B).Tampak samping kanan openbite terkoreksi; (C).Tampak samping kiri openbite terkoreksi

41, 42, 43, 45 masing masing $0,25 \mathrm{~mm}$, grinding mesial gigi 36 dan 46 masing-masing $0,25 \mathrm{~mm}$. Koreksi pergeseran mandibula untuk memperbaiki sendi temporomandibular. Koreksi malrelasi dan malposisi individual dan penyesuaian oklusi. Perawatan pada kasus ini dilakukan dengan alat cekat teknik Edgewise dan pemakaian trainer for braces. Koreksi kebiasaan oklusi yang salah menggunakan alat stabilisasi.

\section{Perawatan}

Trainer for braces dipergunakan setiap pagi atau siang hari selama 1-2 jam,dan pada waktu tidur malam. Evaluasi dilakukan setiap kontrol dan diamati selama 6 bulan. Levelling dan unravelling menggunakan busur stainless steel bulat 0,014 inch dengan multiloop vertical.

Ekspansi rahang atas menggunakan busur stainless steel rectangular 0,016 × 0,022 inch dengan offset di distal gigi 13 dan 23. Pergeseran gigi $35,34,33,32,31$ ke distal dan gigi 41,42 , 43, 45 ke mesial menggunakan busur stainless steel rectangular 0,016 x 0,022 inch diikuti dengan pemakaian elastik intermaksilar kelas III 4,5 oz pada sisi kiri dan 2,5 oz pada sisi kanan.

Perbaikan interdigitasi dan root paralelling pada maksila dan mandibula menggunakan busur stainless steel rectangular $0,017 \times 0,022$ inch dengan first order bend dan dilanjutkan dengan second order bend, selanjutnya dilakukan torquing menggunakan busur stainless steel rectangular $0,019 \times 0,025$ inch untuk memperbaiki inklinasi gigi anterior maksila dan mandibula.

Setelah 12 bulan perawatan ortodontik, terlihat hubungan molar pertama kanan menjadi kelas I, pola skeletal kelas III menjadi kelas I, overjet meningkat dari $0,1 \mathrm{~mm}$ menjadi $2 \mathrm{~mm}$, overbite meningkat dari $0,2 \mathrm{~mm}$ menjadi $2,57 \mathrm{~mm}$, 
Tabel 1. Pemeriksaan sefalogram metode Steiner setelah perawatan

\begin{tabular}{clccc}
\hline No & Analisis skeletal & Normal & Pasien sebelum perawatan & $\begin{array}{c}\text { Pasien setelah } \\
\text { perawatan }\end{array}$ \\
\hline 1. & SNA & $82^{\circ}$ & $82^{\circ}$ & $82^{\circ}$ \\
2. & SNB & $80^{\circ}$ & $85^{\circ}$ & $80^{\circ}$ \\
3. & ANB & $2^{\circ}$ & $-3^{\circ}$ & $2^{\circ}$ \\
4. Go.Gn-SN & $32^{\circ}$ & $31^{\circ}$ & $33^{\circ}$ \\
5. SND & $76 / 77^{\circ}$ & 80 & 79 \\
6. Sudut bidang oklusal-SN & $14^{\circ}$ & $14^{\circ}$ & $14^{\circ}$ \\
7. & I-NA & $4 \mathrm{~mm}$ & $11 \mathrm{~mm}$ & $8 \mathrm{~mm}$ \\
8. & Sudut I-NA & $22^{\circ}$ & $34^{\circ}$ & $18^{\circ}$ \\
9. & I-NB & $4 \mathrm{~mm}$ & $8 \mathrm{~mm}$ & $4 \mathrm{~mm}$ \\
10. Sudut I-NB & $25^{\circ}$ & $26^{\circ}$ & $20^{\circ}$ \\
11. Sudut inter I & $131^{\circ}$ & $126^{\circ}$ & & $130^{\circ}$ \\
\hline
\end{tabular}

garis tengah mandibula yang semula bergeser ke kanan 4,38 mm menjadi 2,53 $\mathrm{mm}$, gigitan terbuka posterior dan clicking telah terkoreksi.

Stabilisasi dan retensi dilakukan menggunakan alat stabilisasi yang dibuat secara individual yang berfungsi untuk memposisikan relasi gigi pada oklusi yang benar.

\section{PEMBAHASAN}

Gangguan oklusi merupakan penyakit yang menimbulkan banyak gajala, namun diperkirakan jumlah penderitanya akan bertambah parah jika perawatan yang dilakukan tidak tepat. Apabila kelainan oklusi dapat diketahui lebih awal maka perawatan akan lebih mudah sedangkan jika terlambat harus dilakukan tindakan yang lebih lanjut

Maloklusi kelas III dapat terjadi karena faktor skeletal yang dipengaruhi oleh faktor genetik dan faktor lingkungan yang lebih mempengaruhi letak gigi dalam lengkung gigi dan relasi gigi. Pada kasus ini pola skeletal pasien menunjukkan pola kelas III dan kebiasaan memajukan mandibula ke arah kanan dikarenakan prematur kontak pada regio kiri mengakibatkan terjadinya gangguan oklusi. Kombinasi perawatan menggunakan alat cekat teknik Edgewise dan trainer for braces menjadi pilihan perawatan untuk koreksi mandibula dan dagu pasien yang bergeser ke kanan, gigitan terbuka posterior dan bunyi click di persendian temporo mandibular.
Pada rahang atas dilakukan ekspansi ke lateral dan pemakaian elastik intermaksilar kelas III memberikan efek sinergi dengan pemakaian trainer for braces untuk koreksi pergeseran mandibula dan relasi gigi. Alat stabilisasi dipergunakan untuk memposisikan gigi pada oklusi yang benar dan koreksi kebiasaan memajukan mandibula yang mengakibatkan oklusi yang salah.

\section{KESIMPULAN}

Perawatan maloklusikelas III tipe dentoalveolar dapat dilakukan dengan perawatan kamuflase menggunakan alat cekat teknik Edgewise sehingga menghasilkan kontak interkuspal yang benar dalam waktu lebih pendek secara signifikan. Penggunaan trainer for braces untuk koreksi pergeseran mandibula dilakukan untuk memberi efek sinergi dalam koreksi maloklusi dan malrelasi gigi pada perawatan dengan alat cekat dan mempersingkat waktu perawatan. Berdasarkan etiologi maloklusi pada pasien, dibutuhkan retensi yang cukup lama untuk kestabilan hasil perawatan dengan alat stabilisasi untuk koreksi kebiasaan oklusi yang salah.

\section{DAFTAR PUSTAKA}

1. Bhalajhi SI. Orthodontics: The Art and Science. 1st ed. New Delhi: Arya (Medy) Publishing House.1997: 407-414 
2. Bishara. S Textbook of Orthodontics Philadelphia: WB Saunders. 2001; 375-411

3. SuryonegoroH.Pencitraantemporomandibular disc order: clicking, http://wwwpdgi-onlinecom diunduh 25 Oktober 2013

4. Widmalm SE; WilliamsWJ, Ang BK, Mckay, DC. localization of tmj sounds to side journal of oral rehabilitation. 2002; 29: 911-917

5. Kobs G, Bernhardt O, Kocher T,Meyer G. critical assesment of temporomandibular joints clicking in diagnosis disc displacement stoamatologija. Baltic Dental and Maxillofacial Journal. 2005; 7: 28-30

6. Renfroe WE. Edgewise. Philadelphia. 1975: 237-335

7. CarlssonGE, Magnusson T. management of temporomandibular disorder in the general dental practise. Chicago. Quintessence Publishing Co Inc. 1992: 101-104

8. Shushu He, Jinhui Gao, Peter Wamalwa, Yunji Wang, Shujuan Zou, Song Chen. Camouflage treatment of skeletal Class III malocclusion with multiloop edgewise arch wire and modified class III elastics by maxillary miniimplant anchorage. Angle of Orthodonthic Journal. 2013; 83(4): 630-640

9. David B Kennedy; Matthew Osepchook. Unilateral Posterior crossbite with mandibular shift: a review. Journal of The Canadian Dental Association. 2005; 71(8): 569-573 